\title{
Melden Sie noch bis zum 28. Februar Ihren hellsten Kopf an!
}

\section{DIE HELLSTEN KQPFE FÜR DIE RADIOLOGIE}

„Die hellsten Köpfe für die Radiologie“ noch bis zum 28. Februar 2020 können Sie als Patin oder Pate Ihre eigenen hellsten Köpfe benennen. Das können Studierende, Famulanten oder PJler sein, die mithilfe des
Programms einen tiefen Einblick in den Deutschen Röntgenkongress erhalten. Mehr Infos gibt es auf www.roentgenkongress.de. Mit der Initiative wollen die Deutsche Röntgengesellschaft (DRG) und der
Berufsverband der Deutschen Radiologen (BDR) den radiologischen Nachwuchs sichern.

\section{So geht's:}

Die Anmeldung Ihrer hellsten Köpfe läuft über die DRG-Geschäftsstelle. Auf www. hellste-koepfe.de finden Sie alle wichtigen Informationen. Bei Fragen wenden Sie sich gern an Ihre Hellste-Köpfe-Ansprechpartnerin bei der DRG: Sandra Ermisch, ermisch@drg.de, 030916 070-29. 